\title{
Methods of Decision Making Support for Innovative Projects Management Using Integrated Ontology
}

\author{
Liliya Chernyakhovskaya \\ Ufa State Aviation Technical University \\ Ufa, Russia \\ lrchern@yandex.ru
}

\begin{abstract}
A purpose of the research is to improve the innovative projects management by refining the design processes and improving the quality and efficiency of decision making. A method of decision making support, including data analysis, acquisition and representation of the explicit and implicit organization knowledge (including cases of the best decision-making practices), search and application of analytical and intelligent decision-making methods, taking into account the characteristics of the various project realization stages, is proposed The main component of the decision making support is an integrated knowledge management ontology, which includes a semantic network of project management ontology and ontology of decision making support tasks, models and methods. With the use of the ontology rules, regulating the innovative project management, as well as algorithms for information and intellectual decision making support, are developed. Application of the decision support methods is shown on innovative project management in power engineering.
\end{abstract}

Keywords-innovative project, decision making support, integrated ontology, ontological engineering, knowledge base, project management ontology

\section{INTRODUCTION}

Organization's innovative activity characterizes the degree of its participation in implementing the innovative activities in general or its separate types for a certain period of time [1]. At the moment, innovative activities of enterprises and organizations are often carried out within its projects realization, so known methods and approaches of project management can be applied for the innovations performed. Innovative projects require increased attention from the company management, as it carries greater risks of non-return on investment than other ongoing projects. A subject area analysis showed that the enterprises innovative projects share of financing by the state or from available external sources remains extremely small. In this regard, enterprises while implementing the innovative projects bear high risks of non-return of its own invested funds, which directly affects the enterprise's working quality as a whole [14]. It follows that the problem of improving the innovative projects management efficiency is extremely relevant for the enterprises and organizations of various activities and scales.

\author{
Anna Malakhova \\ Ufa State Aviation Technical University \\ Ufa, Russia \\ aimalakhova@gmail.com
}

To improve the efficiency of innovative projects management facilitates an intelligent and information decision making support in problem situations that arise while the innovative projects implementation. Innovations, unlike many other processes and phenomena, combine elements of many systems studied separately (technical, technological, organizational, economic, legal, knowledge management), and use different management mechanisms peculiar to each of these systems. This makes it extremely difficult to develop an innovative project system model in a formal setting, where it would be possible to use accurate methods of decision's search. In conducting research an approach to decision making support for innovative projects management based on construction of the integrated knowledge management ontology, which is formed on the basis of system integration of project management ontology and ontology of decision making support tasks, models and methods, is proposed. The processes in innovative projects implementation at power engineering company are considered as a subject area.

\section{ANALYSIS OF THE DECISION MAKING SUPPORT PROBLEM IN INNOVATIVE PROJECT MANAGEMENT}

Based on the data about innovative processes development in Russian Federation from 2000 to 2016 [5], we can say that the level of innovation activity in the country compared to other developed countries remains low. Among the factors that hinder the innovations development the leading role is played by the lack of the own company's funds, the high innovations cost, as well as the uncertainty of the economic benefits from the use of intellectual property. According to the sectoral analysis results from the main innovative activity indicators dynamics, it can be concluded that the most innovative activity is possessed by industrial enterprises $(9.2 \%)$, including enterprises that produce and distribute electricity $(4.1 \%)$ (Fig. 1). Moreover, the larger the organization's scale is, the greater is the aggregate level of its innovation activity.

The power grid company of Bashkortostan Republic is the leading enterprise in the region, providing electricity to the whole republic, as to the largest industrial, fuel, energy enterprises and public institutions, as to the ordinary consumers. Company 
has extensive experience in projects realization of various directions and scale. Only at the moment company is realizing a significant amount of projects carried out both on its own and involving the contractors that requires constant attention from the project office [11]. Practice shows that not every project is conducted involving the project office, and therefore, some necessary project management principles are not always complied, which significantly increases the risk of projects failure or budgets and deadlines increase $[12,16]$.

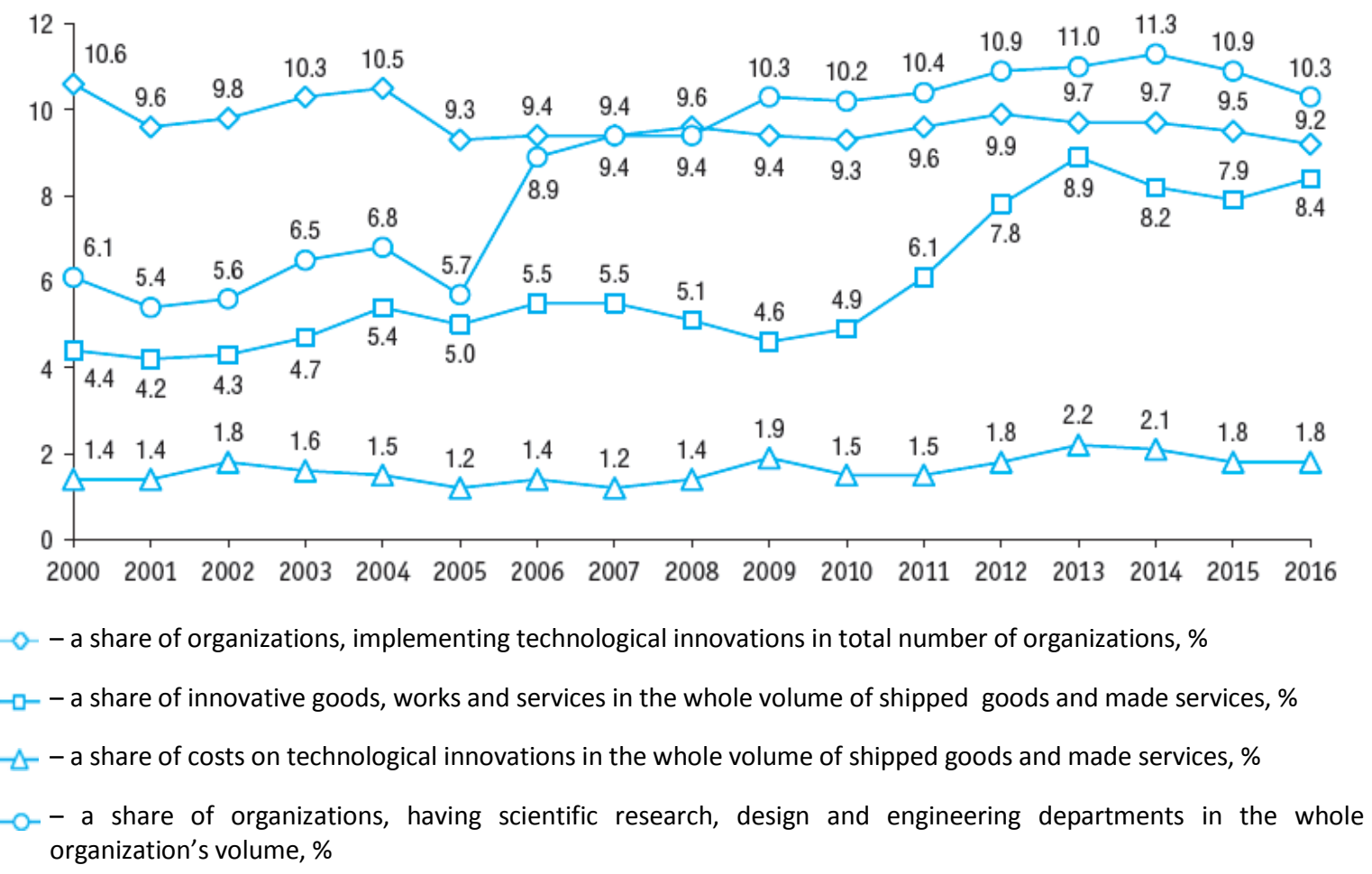

Fig. 1. Innovation activity of the industrial enterprises, including enterprises that produce and distribute electricity

However, project realization, on the one hand, is complicated by the large scale of the project - due to the large number of consumers and the extensive length of electrical networks, the electrical networks connections and power facilities schemes account several tens thousands of elements [8]. On the other hand, the project is complicated by the lack of funding and the qualified staff with the project management skills. These factors lead to the rising in deadlines and budget of the project, which can also lead to the project failure as a whole.

Dispatching personnel from the operational and technological department (OTD) of the company is one of the most highly qualified employees on the enterprise, who often needs to respond operatively and promptly and make decisions in arising emergency situations. A speed of the electricity supply restoration to the consumers directly depends on the decisions taken by them and higher management [7]. Due to the described above factors, it is proposed to provide intellectual and information decision making support on the basis of an integrated knowledge management ontology, which will lead to improvements in validity, accuracy and efficiency of decisions made during the innovative project management.

\section{METHODS OF DECISION MAKING SUPPORT FOR INNOVATIVE PROJECTS MANAGEMENT USING INTEGRATED ONTOLOGY}

As an effective tool for solving of the considered problems a methodology, which is a set of decision making support models, methods and tools based on knowledge engineering technologies that provide information and analytical support for the managing system based on integrated description of decision making requiring situations, systematic combination of knowledge and experts experience, results of mathematical and imitation modeling, is offered to develop and apply. Proposed methodology should provide possibility for a unique "filling" of the models and methods content, depending on the specifics of the project, the data and knowledge about the composition of its stages, the list of estimating indicators and evaluating methods, allowing to automate the decision making process, as well as to create algorithmic support and software for decision making processes, adaptable to a specific industry and project.

As the sources of knowledge within the knowledge base developing process performs the expert's knowledge presented in the form of statements or structured in the form of production rules, as well as the knowledge identified and accumulated on the basis of various innovative processes and projects 
implementing experience. A decision support ontology is a tool for combining of these diverse knowledge, which provides organizing the user's information support on the basis of their requests. Specifics of an innovative project implementation requires representation of various knowledge areas necessary for successful project management [1, 13], which implies a possibility of several ontologies existence, representing conceptualization of the particular project content, as well as the project management knowledge areas (project schedule, cost, deadlines, quality, resources management, etc.). This situation also occurs in domain ontologies development by several users, due to the fact that a particular ontology development bears the imprint of the developer's personality and is to some extent subjective. In order to provide an objective knowledge representation, as well as the concepts display from one knowledge area to another within the decision making rules formation, the decision making support tasks, models and methods ontology and the project management ontology are combined into an integrated knowledge management ontology. On the basis of the obtained ontology knowledge representation models in the form of decision making rules and cases in problem situations, are constructed. Together with the ontology they form the basis of the knowledge base (Fig. 2).

Detecting and saving the cases of decision making in problem situations

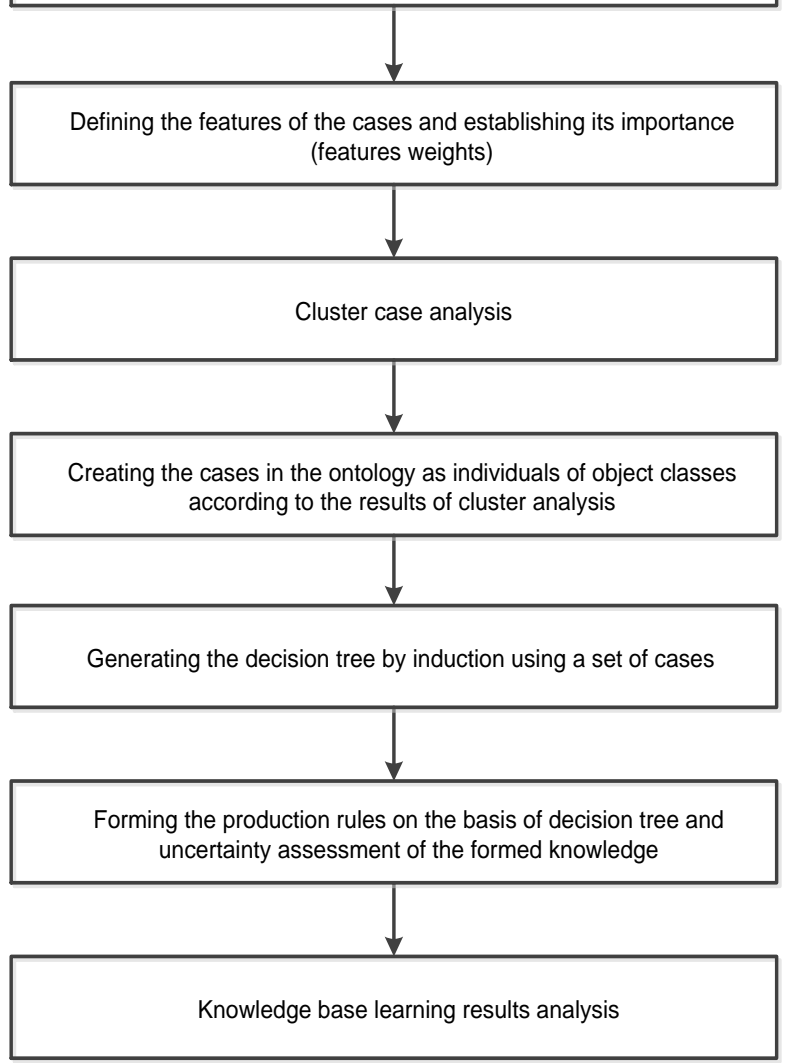

Fig. 2. Methods of the knowledge base construction based on cases
Knowledge base provides the ability to decision making support using methods and algorithms of decision's search, as well as the optimization models and methods and data mining presented in the ontology.

\section{DEVELOPMENT OF THE UNIFIED APPROACH TO THE INTEGRATED ONTOLOGY CREATION}

Ontological engineering is an approach to solving the problems of knowledge effective storage and use for intelligent control systems in specific applications [3]. Ontological engineering involves identification of the main entities classes (basic concepts) in the real interacting processes description, relations between these classes, as well as a set of properties that determine its change and behavior during the interaction. The main goals of the ontological engineering are:

- improving a level of information integration necessary for decision making management;

- improving an efficiency of information search;

- providing a possibility of collaborative knowledge processing based on the unified semantic description of the knowledge area.

According to the proposed approach, the integrated knowledge management ontology Onto can be described as a set of merged ontologies:

$$
\text { Onto }=\left\langle O^{D M}, O^{P M}, \operatorname{Inf} f^{F},\right.
$$

where $O^{D M}$ - a decision making support tasks, models and methods ontology;

$O^{P M}-$ an innovative project management ontology in the considered subject domain;

Inf $f^{F}$ - an inference machine model associated with the ontological system Onto.

An innovative project management ontology $O^{P M}$ is built according to the Guide to the Project Management Body of Knowledge, and supposed to be adjusted according to the particular project specifics. A fragment of the developed ontology is shown in Fig. 3.

The $\operatorname{Inf}{ }^{F}$ inference machine model performs the function of activating the entities and relationships that describe a specific task, which is organizing a dynamic knowledge base component.

Formally ontology includes a set of the domain terms organized into taxonomy, its definitions and attributes, as well as associated axioms and inference rules [4]:

$$
\text { Onto }=<C, \operatorname{Pr}, V, I, R, A, D>
$$

where $C=\left\{C_{1}, C_{2}, \ldots, C_{N}\right\}-$ a set of classes and its interpretations in certain knowledge domain;

$$
\operatorname{Pr}=\left\{\operatorname{Pr}_{1}, \operatorname{Pr}_{2}, \ldots, \operatorname{Pr}_{M}\right\}-\text { classes properties; }
$$


$V=\left\{V_{1}, V_{2}, \ldots, V_{K}\right\}$-properties values. In ontology exists division of the properties on two classes: object properties and data type properties;

$I=\left\{I_{1}, I_{2}, \ldots, I_{L}\right\}-$ a set of individuals, which are defined with the help of axioms and the concrete class properties definition (called facts);

$R=\left\{R_{1}, R_{2}, \ldots, R_{n}\right\}-$ a set of relations;

$A=\left\{A_{1}, A_{2}, \ldots, A_{Q}\right\}-$ a set of axioms;

$D=\left\{D_{1}, D_{2}, \ldots, D_{H}\right\}-$ a set of ontology inference algorithms.

A natural constraint imposed on the set $C$ is its finiteness and not emptiness. The sets $P r, V, R, A$ and $D$ must also be finite, and the boundary cases related to their emptiness are the following.

When $R=0, A=0$, and $D=0$, ontology transforms into a dictionary (Voc) of concepts $C$ and their properties.

For $R \neq 0, A \neq 0$ and $D=0$ ontology represents a thesaurus (Th), including a set of concepts and a set of relations, reflecting a particular subject domain specificity.

In the case when it is a single relationship type $i s \_a$ ("to be a class member") $A^{T} \in A$, thesaurus is transforming into a taxonomy used to represent a hierarchy of concepts related by generalization.
Ontologies are developed in the ontological editor Protégé 5.2.0 [9]. Ontology developed in Protégé can be exported to various formats such as $R D F(S), O W L$, $X M L$ Schema according to the stack architecture of Semantic Web. This allows the ontology to be widely used both by users and makes it machine-readable and compatible with other ontologies and programs. Ontology description is made in $O W L D L$ (Web Ontology Language based on description Logic) [10]. Ontology, developed on the basis of theory and technology of Semantic Web, fully corresponds to the descriptive logic capabilities and allows describing various characteristics of classes and its properties, as well as the relationships between classes that determine the structure of relationships between its individuals [15].

To check the adequacy and integrity of the presented knowledge, the ontology logical model was developed in accordance with descriptive logic [2]. Descriptive logics operate with the terms of concept and role corresponding to the concepts of class and binary relation in the ontology. Descriptive logic concepts of are interesting not so much themselves but as a tool for recording knowledge about the described subject area. This knowledge is divided into general knowledge about the concepts and their interrelations (intensive knowledge) and knowledge about individual objects, their properties and connections with other objects (extensional knowledge). The former are more

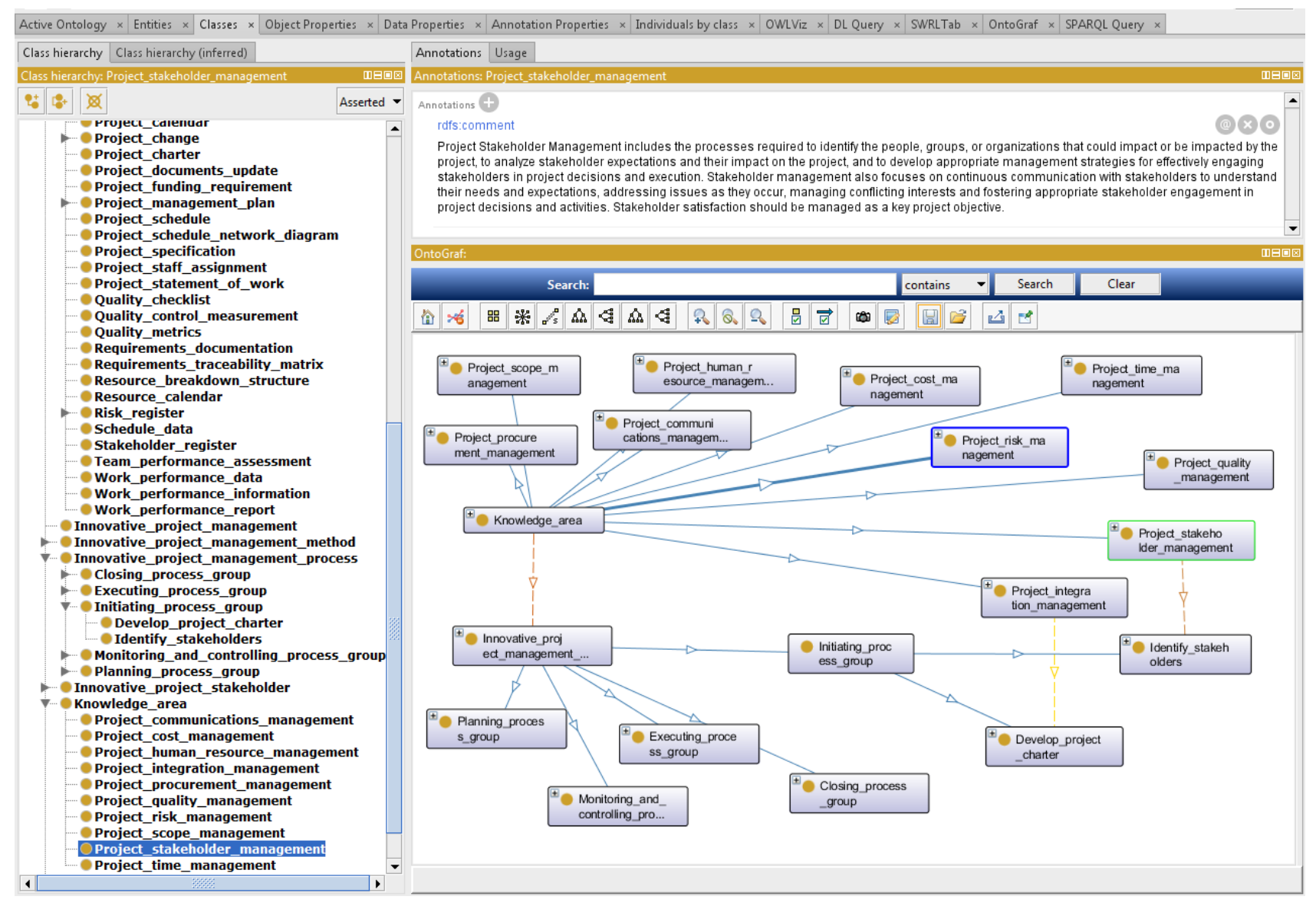

Fig. 3. A fragment of the innovative project management ontology 
stable and constant, while the latter are more subject to modifications. According to this division, knowledge recorded by descriptive logic is divided into a set of terminological axioms ( $T$-Box $)$ and a set of statements about individuals $(A-B o x)$.

Combining of the ontologies is carried out using the built-in function merge ontologies, which provides the operation of equivalent classes, entities and synonyms (in the context of the subject area) combining, with the experts participation. As a result, in the semantic network of integrated ontology the object relationships between the object's classes from the innovative process management ontology and from the decision making support tasks, models and methods ontology, are displayed.

\section{CONCLUSION}

Thus, formulating and solving the fundamental problem of the decision making support complex tools development within the innovative projects management, which includes the knowledge engineering models, methods and tools, integrated on the basis of ontological analysis, will provide new theoretical and practical results, relevant and important as for development of the intelligent control systems theory, as well as for development of the project management theory and socio-economic systems strategic management.

\section{ACKNOWLEDGMENT}

The work is supported by RFBR grant № 18-0000345 (18-00-00238) "Methods and models of decision making support in innovative projects management based on knowledge engineering".

\section{REFERENCES}

[1] A Guide to the Project Management Body of Knowledge (PMBoK Guide). - Project Management Institute. 2017. Pensylvanya: Sixth Edition. PMI Publications, 2017.

[2] An Evaluation of Description Logic for the Development of Product Models. Xenia Fiorentini, Sudarsan Rachuri, Mahesh Mani, Steven J. Fenves, Ram D. Sriram. Manufacturing Systems Integration Division, Manufacturing Engineering Laboratory, 2008
[3] Chernyakhovskaya, L.R. Decision-making support at strategic business management on the basis of knowledge engineering: monograph - Ufa: ANRB, Gilem, 2010. - 128 pp. (in Russian)

[4] Gruber, T. R. A translation approach to portable ontology specifications // Knowledge Acquisition, 5 (2), 1993, pp. 199220

[5] Indicators of Innovation in Russian Federation: 2018: Data book / N. Gorodnikova, L. Gokhberg, K. Ditkovskiy et al.; National Research University Higher School of Economics. Moscow: HSE, 2018. (in Russian)

[6] Introduction to Machine Learning. Ethem Alpaydin. - The MIT Press Cambridge, Massachusetts, London, England, 2004

[7] Kobets B.B., Volkova I.O. Innovative development of electric power industry on the basis of Smart Grid. - M.: IAZ Energy, 2010. - 208 pp. (in Russian)

[8] Massel L.V., Massel A.G. Technologies and tools for intelligent decision support in extreme situations in electric power industry / Computing technologies, 2013. - V . 18. - P. 37 - 44. (in Russian)

[9] Official documentation on Protégé. URL: http://protrgrwiki.stanfotd. edu/index.php/ProtegeUserDocs (Access date: 15.02.2019).

[10] OWL 2. Web Ontology Language. Document Overview (Second Edition). URL: http://www.w3.org/TR/owl2overview/ (Access date: 01.02.2019).

[11] Proceedings of the VIII Meeting of the young power engineers of Bashkortostan. . - Ufa.: Informreklama, 2018. 480 pp. (in Russian)

[12] «PMI's Pulse of the Profession: Capturing the Value of Project management». URL: https://www.pmservices.ru/project-managementnews/cennost-upravleniya-proektami-otchyot-pmi-2015-godal (Access date: 26.01.2019)

[13] Russell D. Archibald "Managing High-Technology Programs and Projects" / translated from English E.V. Mamontova. M.:DmK Press, IT, 2006. - 472 pp. (in Russian)

[14] Russell D. Archibald, Shane C. Archibald "Leading and managing innovation: what every executive team must know about project, program and portfolio management". Second edition. - CRC Press, 2016. - 116 pp.

[15] Spinning the Semantic Web. Bringing the World Wide Web to Its Full Potential. Edited by Dieter Fensel, James A. Hendler, Henry Lieberman and Wolfgane Wahlster. Foreword by Tim Berners-Lee. - The MIT Press, Cambridge, Massachusetts, London, England, 2003. - 503 pp.

[16] Standish Group 2015 Chaos Report - Q\&A with Jennifer Lynch. URL: https://www.infoq.com/articles/standish-chaos2015 (Access date: 26.01.2019) 